\title{
A Comparative Analysis of Cogging Torque Reduction in BLDC Motor Using Bifurcation and Slot Opening Variation
}

\author{
G. Suresh Babu' ${ }^{1}$, T. Murali Krishna ${ }^{1}$, B. Vikram Reddy ${ }^{2}$ \\ ${ }^{1}$ Department of Electrical \& Electronics Engineering, Chaitanya Bharathi Institute of Technology, Gandipet, Hyderabad, India \\ ${ }^{2}$ Department of Electrical \& Electronics Engineering, Chaitanya Bharathi Institute of Technology, Hyderabad, India
}

\section{Email address:}

gsb67@cbit.ac.in (G. S. Babu), tmurali5@gmail.com (T. M. Krishna)

\section{To cite this article:}

G. Suresh Babu, T. Murali Krishna, B. Vikram Reddy. A Comparative Analysis of Cogging Torque Reduction in BLDC Motor Using Bifurcation and Slot Opening Variation. American Journal of Electrical Power and Energy Systems. Vol. 4, No. 5-1, 2015, pp. 9-12. doi: $10.11648 /$ j.epes.s.2015040501.12

\begin{abstract}
The utility of PM-BLDC machines is extending its tentacles in industrial arena. The key features of BLDC machines include high starting torque density and extending speed range, though the cogging torque is a threat for its performance. Various techniques have been devised to minimize cogging torque, out of which two approaches Bifurcation and Slot Opening methods have been focused in this paper. Usage of SPEED Software in comparing the reduction of cogging torque for the above two techniques is the highlight of this paper.
\end{abstract}

Keywords: Cogging Torque, BLDC Motor, Bifurcation

\section{Introduction}

Permanent-Magnet BLDC machines are propelled in industrial applications and the lack of sliding contacts makes them reliable and their characteristics make them suitable for sensor less drive applications [2], [3].

Nevertheless, they are affected by a few drawbacks such as high costs of PM materials and cogging torque which lowers torque quality and affects smooth running of the machine, producing vibrations, ripples in output torque and mechanical noise. In these machines, Internal Permanent Magnet machines show better performance in flux weakening operation [4] and achieve higher flux density due to the small air gap that allows imposing a magnetizing current effectively but have higher torque ripple and many design issues compared to Surface Permanent Magnet machines [5], [2].

Load torque comprises cogging torque ripple and the load torque. The cogging torque reduction methods can be obtained from analytical expression (derived by the energy method and the Fourier series analysis) or by FEA simulations. This paper presents the analysis and comparison of different low cost cogging torque reduction methods which can be practically applied to IPM machines. The peakto-peak torque ripple of the cogging torque, peak-to-peak rated torque profile, mean value of rated torque and efficiency will be used as index values to compare and evaluate the different methods [6] by FEA simulation on a known 4-pole machine, used as a test bed to identify the most effective ones for a given starting geometry.

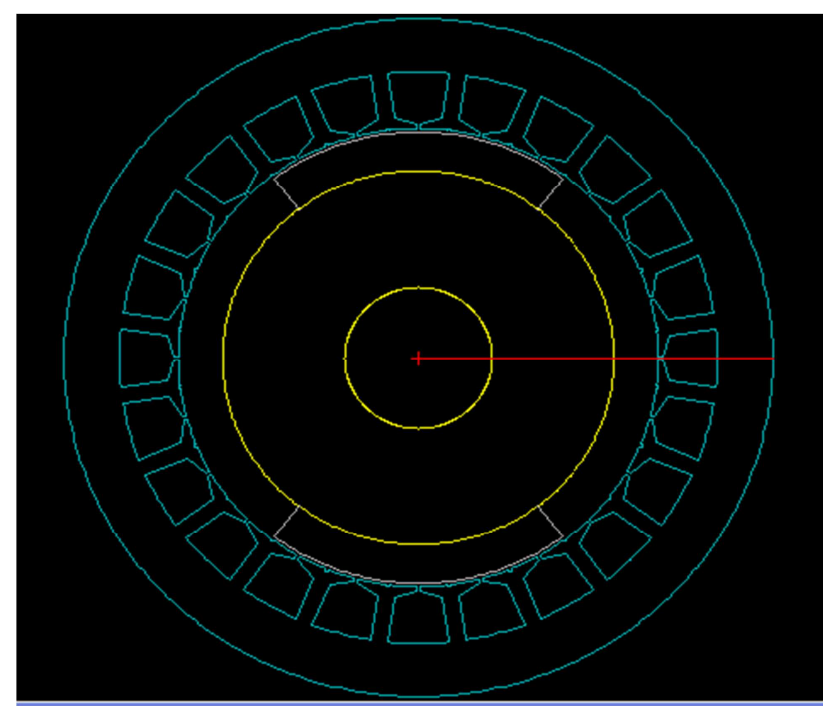

Fig. 1. Motor Simulation in SPEED considered for the Project.

\section{Cogging Torque}

Cogging torque is caused by the alignment of stator and 
rotor at low speeds and produced by the force of attraction between the stator teeth and PM rotor. This is torque which is present even without excitation. A descriptive equation according to the definition is given as,

$$
\mathrm{T}_{\operatorname{cogg}}=-\left(\frac{\partial W}{\partial \theta}\right)
$$

Cogging torque produces zero net work, but it acts as a disturbance superimposed on the electromagnetic torque generated during machine operation and the cogging torque period is linked with the number of slots and poles.

\section{Cogging Torque Reduction Methods}

This paper presents cogging torque reduction methods for the commercial and military grade machines with less cost and effective means i.e., Bifurcation with reduced Tooth Width (TW) and Slot Opening (SO) variations

A. Reduced Stator Tooth with Bifurcation

This is one of the methods in reducing cogging torque in BLDC motors i.e. the reduction of stator tooth with bifurcation [1].

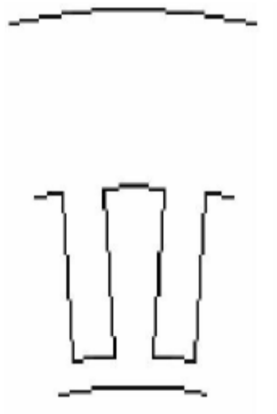

(a) Specified

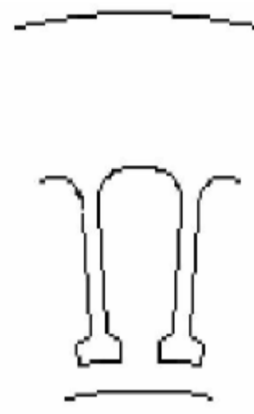

(b) Reduced

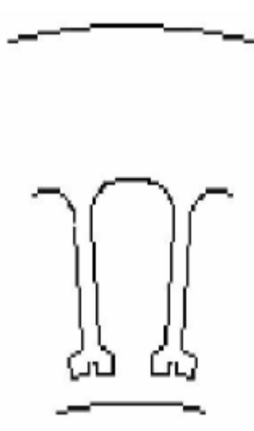

(c) Bifurcated
Fig. 2. Reduced Stator TW and Bifurcation modification to Original Motor.

In fig (a), the original stator slots have been showed. In this case, the reluctance variation with respect to the rotor rotation is large and the cogging torque produced is also very large. The magnitude of cogging torque depends on the variation of reluctance w.r.t. rotor rotation.

In fig (b), the slots width is reduced. In this case the net amount of iron to which the PM of rotor is reduced and the force of attraction between the stator teeth and rotor PM decreases. This reduces the cogging torque. The net amount of cogging torque reduced in this method is low.

In fig (c), the stator tooth is bifurcated. This helps in maintaining the change in airgap reluctance constant w.r.t. the rotor rotation. Hence the cogging torque is reduced to the greater amount of nearly $40 \%$ when compared to normal design. This bifurcation results in reducing the efficiency of $2 \%$.

The resultant graphs for the three cases are plotted.

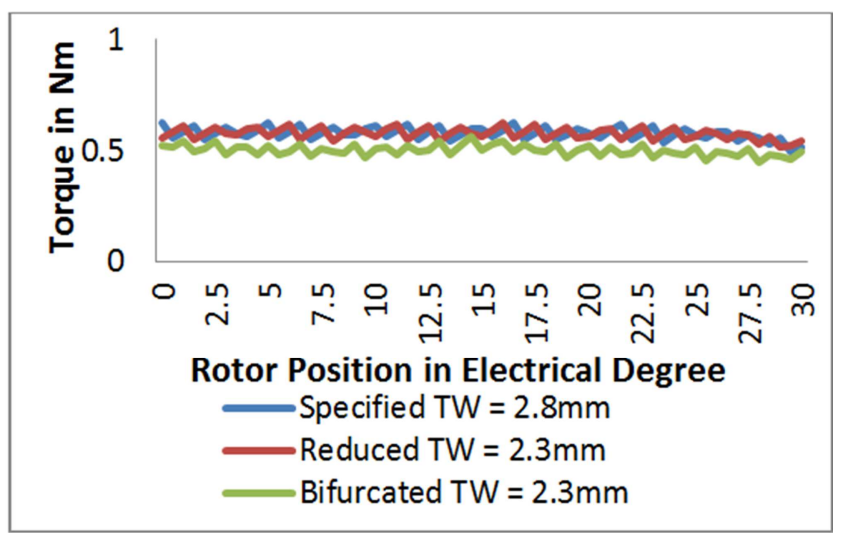

Fig. 3. Graph showing different Torque for Reduced Stator TW and Bifurcation modification to Original Motor.

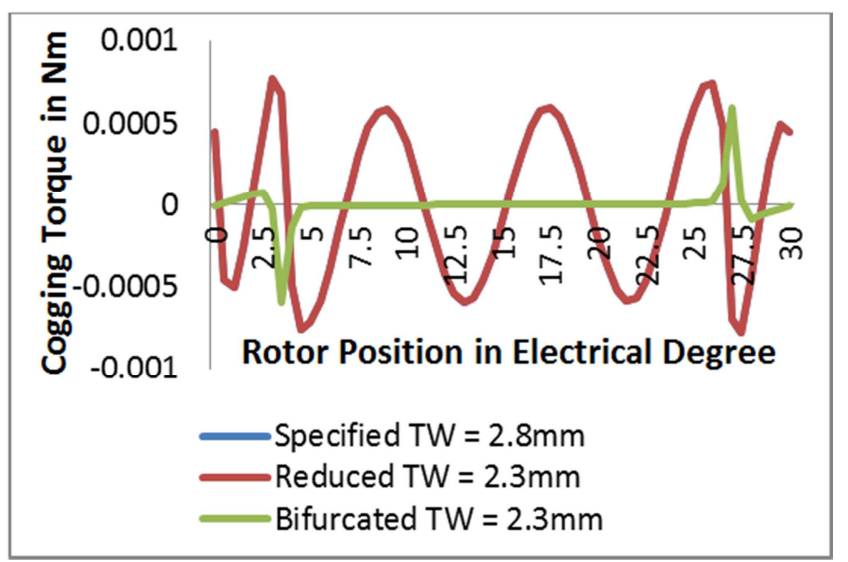

Fig. 4. Graph showing different Cogging Torque for Reduced Stator TW and Bifurcation modification to Original Motor.

\section{B. Slot Opening Variation}

Slot opening has an effective impact on the cogging torque. This is the direct and noticeable one. Since the cogging torque is generated by the interaction of the stator teeth and the rotor magnetic field, the slot opening width has a significant impact on this phenomenon. Moreover, also the back-EMF harmonic content depends on the air gap flux density distribution. Therefore, the slot opening width has to be chosen very carefully in order to optimize the machine design. Generally the cogging torque and the harmonic content of the back-EMF decrease as the slot opening become smaller. Since the slot opening influences the winding manufacturing and costs, the choice of the optimal width is a trade-off between cost and performance.

The slot opening shouldn't be minimum, this causes problems for cooling and the rated loading cannot be imposed. And also it shouldn't be more, because this causes increasing the cogging torque. Simulation is done for various slot opening cases to do trade off in reducing maximum cogging torque. 


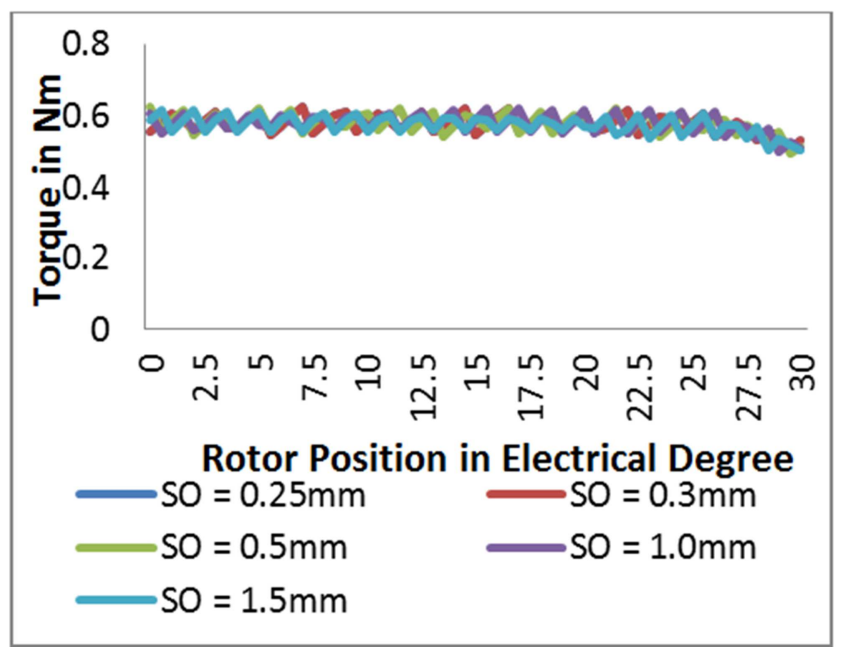

Fig. 5. Graph showing different Torque for Slot Opening variation.

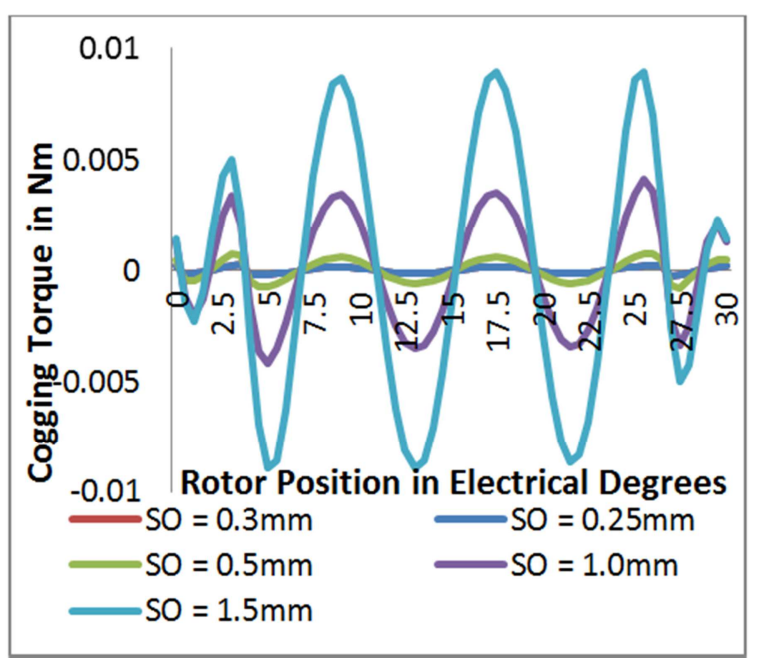

Fig. 6. Graph showing different Cogging Torque for Slot Opening variation.

\section{Results Comparision}

Table I. Tabular representation of Results comparison.

\begin{tabular}{llllllll}
\hline METHOD & & $\mathbf{T}_{\text {rated }}[\mathbf{N m}]$ & $\mathbf{T}_{\text {rated }}[\mathbf{\%}]$ & $\mathbf{T}_{\text {cogg }}[\mathbf{N m}]$ & $\mathbf{T}_{\text {cogg }}[\mathbf{\%}]$ & $\mathbf{E f f}$ & Eff [\%] \\
\hline & $0.25 \mathrm{~mm}$ & 0.516 & 1.9 & $1.8 \mathrm{e}-4$ & -76.83 & 89.19 & 1.4 \\
Slot Opening & $0.3 \mathrm{~mm}$ & 0.515 & 1.7 & $2.55 \mathrm{e}-4$ & -67.18 & 89.09 & 1.3 \\
& $0.5 \mathrm{~mm}$ & 0.506 & 0 & $7.7 \mathrm{e}-4$ & 0 & 87.89 & 0 \\
& $1 \mathrm{~mm}$ & 0.429 & -15.2 & $4.17 \mathrm{e}-3$ & 436.67 & 75.05 & -14.6 \\
Reduced TW \& & $1.5 \mathrm{~mm}$ & 0.27 & -46.64 & $8.9 \mathrm{e}-3$ & 1045.4 & 47.71 & -45.72 \\
Bifurcation & $2.8 \mathrm{~mm}$ & 0.506 & 0 & $7.78 \mathrm{e}-4$ & 0.12 & 87.89 & 0 \\
& $2.3 \mathrm{~mm}$ & 0.499 & -1.3 & $7.7 \mathrm{e}-4$ & 0 & 86.49 & -1.6 \\
\hline
\end{tabular}

\section{Conclusion}

Two methods are compared on a common reference machine (24-slot 4-pole IPM machine) by extensive FEM simulations. The results summarized in Table I show that cogging torque reduction techniques developed can be easily applied to IPM machines. For best results, during optimization it is advisable not to focus only on cogging torque reduction but to monitor the side effects as well.

From this paper, Slot Opening variation method produces on efficient solution in reducing cogging torque and is less cost when compared to the Bifurcation method.

But Slot Opening method suffers from a tradeoff between cost and total rating usage. If Slot Opening is minimum, the motor cannot be used to its full potential and only $70 \%$ of it can be utilized. But there is no trade off to Bifurcation Method but Tooth Width should be sufficient to hold the weight of conductor. This method increases efficiency.

\section{Motor Specifications}

$\begin{array}{ll}\mathrm{V}_{\mathrm{dc}} & 48 \mathrm{~V} \\ \mathrm{I}_{\text {rated }} & 5 \mathrm{~A} \\ \text { Connection } & \mathrm{Star} \\ \text { Speed } & 4140 \mathrm{rpm} \\ \text { Number of phases } & 3 \\ \text { Outer radius } & 48 \mathrm{~mm}\end{array}$

$\begin{array}{ll}\text { Inner radius } & 32.5 \mathrm{~mm} \\ \text { Stator yoke } & 7.5 \mathrm{~mm} \\ \text { No. of slots } & 24 \\ \text { Rotor yoke } & 16.5 \mathrm{~mm} \\ \text { Shaft radius } & 10 \mathrm{~mm} \\ \text { Air gap } & 0.5 \mathrm{~mm} \\ \text { Magnet length } & 5.5 \mathrm{~mm} \\ \text { No. of poles } & 4 \\ \text { Magnet pole arc } & 150^{\circ}\end{array}$

\section{Acknowledgements}

The authors express deep sense of gratitude to the management of CBIT and authorities of RCI, Hyderabad for having encouraged their sincere attempts in achieving greater heights.

\section{References}

[1] R. Somanatham, P. V. N. Prasad, and A. D. Rajkumar, "Reduction of Cogging Torque in PMBLDC Motor with Reduced Stator Tooth Width and Bifurcated Surface Area using Finite Element Analysis," IEEE 0-7803-9772-X, June 2006.

[2] N. Bianchi and T. M. Jahns, "Design, analysis, and control of interior PM synchronous machines," in IEEE IAS Annu. Meeting, Seattle, Oct. 12, 2004. 
[3] D. Novotny and T. Lipo, Vector Control and Dynamics of AC Drives. Oxford, U.K.: Oxford Science Publications, 2000.

[4] T. M. Jahns, "Flux-weakening regime operation of an interior permanent-magnet synchronous motor drive," IEEE Trans. Ind. Appl., vol. IA-23, no. 4, pp. 681-689, Jul./Aug. 1987.

[5] G. Pellegrino, A. Vagati, P. Guglielmi, and B. Boazzo, "Performance comparison between surface-mounted and interior pm motor drives for electric vehicle application," IEEE Trans. Ind. Electron., vol. 59, no. 2, pp. 803-811, Feb. 2012.
[6] G.-H. Kang, Y.-D. Son, G.-T. Kim, and J. Hur, "A novel cogging torque reduction method for interior-type permanentmagnet motor," IEEE Trans. Ind. Appl., vol. 45, no. 1, pp. 161-167, Jan.-Feb. 2009.

[7] N. Bianchi and S. Bolognani, "Design techniques for reducing the cogging torque in surface-mounted PM motors," IEEE Trans. Ind. Appl., vol. 38, no. 5, pp. 1259-1265, Sep./Oct. 2002. 